\section{A case study on Asthma-COPD Overlap (ACO) is independent from COPD}

\author{
Divya Khanduja ${ }^{1 *}$, NC Kajal ${ }^{2}$, Libin Mathew $^{3}$ and \\ Deepak Garg ${ }^{1}$
}

'Junior Resident, Department of Pulmonary Medicine, Government Medical College, Amritsar, Punjab, India

${ }^{2}$ Professor, Department of Pulmonary Medicine, Government Medical College, Amritsar, Punjab, India ${ }^{3}$ Senior Resident, Department of Pulmonary Medicine, Government Medical College, Amritsar, Punjab, India
Received: 14 July, 2021

Accepted: 22 July, 2021

Published: 23 July, 2021

*Corresponding author: Divya Khanduja, Junior Resident, Department of Pulmonary Medicine, Government Medical College, Amritsar, Punjab, India, Tel: +91-9582969172; Email: divyakhandujalhmc@gmail. com; khanduja.divya@gmail.com

Keywords: Asthma; COPD; Asthma-COPD overlap; Eosinophilia; ACO

https://www.peertechzpublications.com

Check for updates

\begin{abstract}
As we know that, Asthma and chronic obstructive pulmonary diseases are well characterized diseases, they can co-exist as asthma-COPD overlap (ACO). The coexistence of asthma-chronic obstructive pulmonary disease overlap (ACO) in Chronic Obstructive Pulmonary Disease (COPD) patients is often unrecognized. In patients with a primary diagnosis of COPD, the identification of ACO has got implication for better prognosis and treatment. Such patients experience frequent exacerbations, poor quality of life, rapid decline in lung function and high mortality than COPD alone. Inhalational steroids provide significant alleviation of symptoms in such patients and some studies suggest that the most severe patients may respond to biological agents indicated for severe asthma. We report a case of 61 year-old-male who presented with nocturnal and early morning breathlessness, cough and wheezing episodes for past 2-3 weeks. He was diagnosed with COPD 6 years back as patient has history of biomass fuel exposure since childhood. The criteria to diagnose asthma-COPD overlap (ACO) include positive bronchodilator response, sputum eosinophilia or previous diagnosis of asthma, high IgE and/or history of atopy. There is scarcity of literature available in country like India. We highlight the importance of identification of Asthma COPD overlap as different phenotype from COPD or asthma alone as it is challenging to diagnose ACO in India. In our case, patient was diagnosed with ACO, based on the spirometry findings and the sputum findings have helped in the modification of his treatment and causing alleviations of symptoms and better clinical outcome.
\end{abstract}

\section{Introduction}

The global burdens of asthma and Chronic Obstructive Pulmonary Disease (COPD) are increasing, each of which was estimated to affect respectively approximate 339 million and 251 million people worldwide in 2016 [1]. Asthma is a heterogeneous disease, usually characterized by chronic airway inflammation. It is defined by the history of respiratory symptoms such as wheeze, shortness of breath, chest tightness, and cough that vary over time and in intensity, together with variable expiratory airflow limitation [2]. Chronic Obstructive Pulmonary Disease (COPD) is a common, preventable and treatable disease that is characterized by persistent respiratory symptoms and airflow limitation that is due to airway and/or alveolar abnormalities usually caused by significant exposure to noxious particles or gases [3]. Although, Chronic Obstructive
Pulmonary Disease (COPD) and asthma are different entities but, in some patients, they can share features of both the diseases. "Asthma-COPD Overlap (ACO)" as descriptive term was used to define these patients. ACO prevalence has varied widely in studies: from $0.9 \%$ to $11.1 \%$ in the general population, from $11.1 \%$ to $61.0 \%$ in asthma patients, and from $4.2 \%$ to $66.0 \%$ in COPD patients [4]. There is little data available on ACO in India. In 2015, the Global Initiative for Asthma (GINA) and the Global Initiative for Chronic Obstructive Lung Disease (GOLD) released a joint statement which was then called "asthma COPD overlap syndrome (ACOS)", as persistent airflow limitation with several features usually associated with asthma and several features usually associated with COPD [5]. In 2017, the American Thoracic Society and the National Heart, Lung and Blood Institute published a joint workshop report on ACO. It was concluded that ACO, like asthma and COPD, 
doesn't represent a single discrete disease entity [6]. Thus, it is important to diagnose the patients with ACO as they have higher chances of exacerbations which are more severe than as compared with patients of asthma or COPD alone. Herein we report a case of ACO sharing clinical features of both asthma and COPD.

\section{Case presentation}

A 61-year-old male presented at emergency with complaints of nocturnal and early morning shortness of breath, cough with expectoration and wheezing episodes for past 2 weeks. He gave history of similar episodes for past 6-7 years. There is no history of breathlessness in childhood. Patient was diagnosed with COPD 6 years back. There is history of progressive worsening of exertional dyspnoea, seasonal variation of breathlessness with symptoms on exposure to dust and were more during cold climate that often need hospitalization since past 6-7 years. He gave history of biomass fuel exposure since childhood, might be the causative factor in developing emphysematous changes in this case. He is non-smoker, non-alcoholic. There is no history of tuberculosis in past and family. On examination, patient was slightly dyspnoeic without the use of accessory muscles, with a blood pressure of $132 / 90 \mathrm{mmHg}$, pulse rate of $108 / \mathrm{min}$, respiratory rate of $34 / \mathrm{min}$, and saturation of $92 \%$ on room air. On general physical examination, clubbing was present and shape of the chest was barrel shaped. On auscultation, bilateral rhonchi with decreased breath sounds were present.

Laboratory findings revealed haemoglobin of $12.9 \mathrm{~g} / \mathrm{dl}$, white blood count of 10,600 , ESR-28, RBS-104mg/dl, serum bilirubin-0.41, SGOT-22, SGPT-19, serum creatinine-0.98. Peripheral eosinophilia was present (AEC- 766). His sputum for acid fast bacilli, gram stain and culture and fungus were negative. Sputum for CBNAAT (Xpert MTB/RIF) showed MTB not detected. Mantoux test and serology of HIV were negative. We should rule out other conditions associated with eosinophilia such as parasitosis, allergic bronchopulmonary aspergillosis or Churg Strauss syndrome.

As we can see in Figure 1, Chest radiograph showed bilateral hyperinflation with flattening of diaphragm and obliteration of right sided costophrenic angle. As the patient was not affordable, patient denied for HRCT chest which was advised to the patient.

As we can see in Figure 2 and Table 1, Spirometry showed: FEV1- 57\%, Post bronchodilator FEV1-69\%, FEV1/FVC- 59\%, Post Bronchodilator FEV1/FVC- 61\%, Post bronchodilator increase in FEV1- 20\%.

Patient was on ICS and LABA combination for the treatment. Owing to these findings of reversibility of airflow limitation and peripheral eosinophilia. Patient was considered for the diagnosis of asthma COPD overlap (ACO). Thus, patient started with the ICS, LABA and LAMA combination. After 4 week follow up, patient was clinically improved with no nocturnal dyspnoea and did not have wheezing with decrease in peripheral eosinophilia (AEC-225). Currently patient is following this pharmacological therapy and is clinically improved.

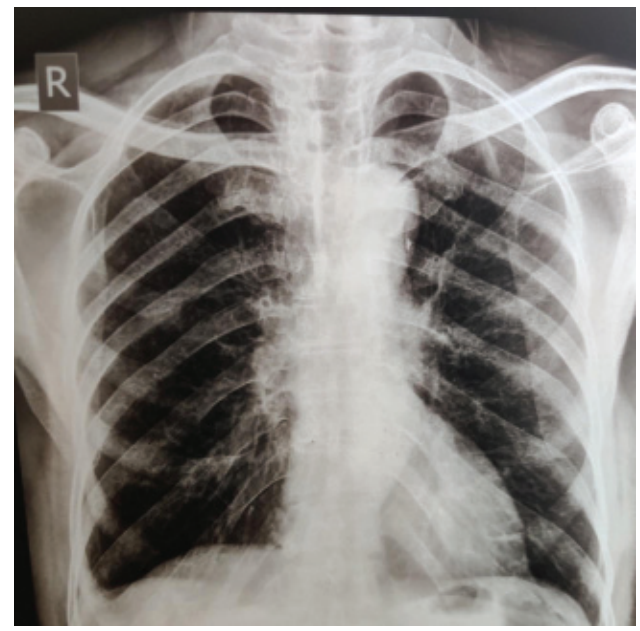

Figure 1: CXR PA View: Bilateral hyperinflation with flattening of diaphragm and obliteration of right sided costophrenic angle.

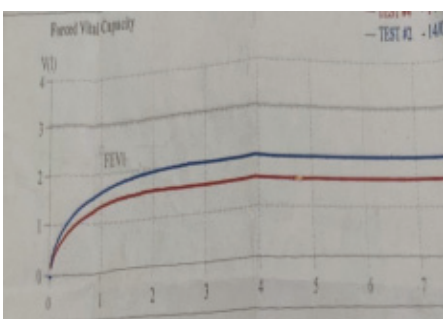

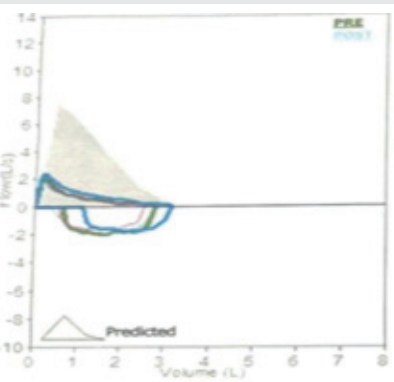

(B)
Figure 2: Showing (a) flow-volume curve and (b) volume-time curve of spirometry.

Table 1: Spirometric interpretation of figure 2.

\begin{tabular}{|c|c|c|}
\hline & Litres & Percentage \\
\hline Pre FEV1 & 1.44 & 57 \\
\hline Post FEV1 & 1.74 & 69 \\
\hline Pre FEV1/FVC & & 59 \\
\hline Post FEV1/FVC & & 61 \\
\hline \% Increase in FEV1 & & 20 \\
\hline
\end{tabular}

\section{Discussion}

Asthma and Chronic obstructive pulmonary disease (COPD) are umbrella labels for heterogeneous conditions characterized by chronic airway and/or lung disease [2]. COPD and asthma each include several different clinical phenotypes, and are likely to have several different underlying mechanisms, some of which may be common to both asthma and COPD. The term 'asthma COPD overlap' (ACO) simply describes patients who features of both asthma and COPD [2]. In 1961, Orie and colleagues proposed the concept of overlap between COPD and asthma as all the airway diseases, including asthma, emphysema and chronic bronchitis, should be considered a single disease with common genetic origins which was subsequently known as "Dutch hypothesis" [7]. In 2015, the Global Initiative for Asthma (GINA) and the Global Initiative for Chronic Obstructive Lung Disease (GOLD) released a joint statement which was then called "asthma COPD overlap syndrome (ACOS)", as persistent 
airflow limitation with several features usually associated with asthma and several features usually associated with COPD [5]. Later, the word syndrome was removed as ACO have several different clinical manifestations and didn't fulfil the criteria to known as syndrome.

Asthma is a heterogenous and inflammatory disease affecting large and small respiratory tracts but not the lung parenchyma, and contains clusters of demographical, clinical and pathophysiological characteristics supported by different pathophysiological processes [8]. This heterogeneity may be explained by the complexity of dysregulated innate and adaptive inflammatory responses to exogenous allergens and proteases leading to the spectrum of abnormal tissue remodelling, where type 2 cytokines such as interleukin (IL)-4, IL-13 and IL-5 primarily promote airway eosinophil infiltration, mucus hypersecretion, bronchial hyperresponsiveness and mast cell activation [9]. Major subpopulations of asthmatics have molecular signatures of $\mathrm{T}$ helper 2 (Th2)-inflammation and airway obstruction that markedly respond to inhaled corticosteroid (ICS) [10].

COPD is defined as a common, preventable and treatable disease that is characterized by persistent respiratory symptoms and airflow limitation that is due to airway and/or alveolar abnormalities usually caused by significant exposure to noxious particles or gases and influenced by host factors including abnormal lung development [3]. In addition to cigarette smoking, known as the most common COPD risk factor [11], the susceptibility could be influenced by genetic factors and abnormal lung growth. Unlike asthma, CD4+ T helper 1 (Th1) cells, CD8 + cytotoxic T (Tc) cells, neutrophils and macrophages predominantly affect the small airways and the lung parenchyma leading to mucus hypersecretion, alveolar wall destruction (emphysema) and small airway fibrosis in COPD. The small airway narrowing induced by pro-inflammatory cell infiltration, luminal exudates, wall thickening, and the loss of small airways associated with emphysema increases airway obstruction. The airflow limitation progressively leads to gastrapping in peripheral lungs during expiration on exercise, resulting in dynamic hyperinflation which is postulated to be the main mechanism of exertional dyspnoea [12]. Thus bronchodilators, Long-Acting Muscarinic Antagonists (LAMA) and long acting beta2-agonists (LABA), are commonly used as the pharmacological therapy for COPD and are known to reduce lung hyperinflation, dyspnoea and exercise endurance [13]. Some COPD patients releases type 2 cytokines, may manifests clinical features as asthma such as bronchodilator reversibility, increase in peripheral eosinophilia and also in airways, these phenotypes thought to be associated to ACO [14].

In 2016, a global expert panel discussion between various specialists from North America, Western Europe and Asia, described a consensus on ACO which was based on major and minor clinical, spirometric and laboratory criteria [15]. According to this consensus, the patients who meet all the three major criteria and at least one minor criterion be considered for the diagnosis of ACO.
- Major criteria include [15]:

1. Persistent airflow limitation [post-bronchodilator FEV1/FVC $<0.70$ ] in individuals 40 years of age or older.

2. At least 10 pack-years of tobacco smoking or equivalent indoor or outdoor air pollution exposure [ex. biomass]

3. History of asthma before 40 years of age or bronchodilator response of $>400 \mathrm{ml}$ in FEV1

- Minor criteria include [15]:

1. History of atopy or allergic rhinitis

2. Bronchodilator response of FEV1 $>200 \mathrm{ml}$ and $12 \%$ from baseline values on 2 or more visits

3. Peripheral blood eosinophil count of $>300$ cells/microL

Management of Asthma and COPD is different. For Asthma patients ICS is essential for treatment and for COPD patients LAMA and/or LABA should be given initially. ICS reduce serum IgE and sputum eosinophils, and improves lung function and patient-reported symptom scores in some patients with ACO. ICS should be given earlier in asthma patients and in COPD patients, ICS should be given with a history of more than and equal to 2 exacerbations requiring OCS and/or increased blood eosinophils (>300/microL) [2,3]. Importantly, in asthma patients long-acting beta-2 agonists (LABA) should be given in combination with ICS as LABA alone have been associated with an increased risk of asthma-related death when not given in combination with an ICS, thus LABA should not be prescribed as a single therapy in asthma [16]. For patients with ACO, ICS containing treatment is essential to reduce risk of severe exacerbations and death. LABA and/or LAMA usually needed as add-on [2]. Triple therapy (ICS+LABA+LAMA) has found to be more effective as comparison to ICS+LABA combination as it improves lung function and reduce the chances of exacerbations [17]. Therefore, LAMA should be added with ICS and LABA in ACO patients, if symptoms are not controlled with ICS and LABA combination to prevent risk of recurrent exacerbations.

\section{Conclusion}

ACO as a clinical entity have both the clinical features of asthma and COPD, it has been associated with increased disease burden and imposed challenges for diagnosis and management of these patients. According to the current definitions of asthma and COPD, ACO has been described as a subgroup of patients with several different clinical phenotypes reflecting different underlying mechanisms. Due to lack of data availability in India, it is challenging to diagnose ACO. This is important to recognise ACO in COPD patients because an appropriate diagnostic measures for the ACO patients may allow better-targeted therapy, and helped to alleviate the worsening symptoms and recurrent exacerbations, thus, improved clinical course of the disease. This is much needed in COPD and asthma patients.

Citation: Divya K, Kajal NC, Mathew L, Garg D (2021) A case study on Asthma-COPD Overlap (ACO) is independent from COPD. Arch Pulmonol Respir Care 7(1): 


\section{References}

1. Vos T, Abajobir AA, Abate KH, Abbafati C, Abbas KM, et al. (2017) Global, regional, and national incidence, prevalence, and years lived with disability for 328 diseases and injuries for 195 countries, 1990-2016: A systematic analysis for the global burden of disease study 2016. Lancet 390: 1211-1259. Link: https://bit.ly/3wRKtWB

2. Global Initiative for Asthma. Global strategy for asthma management and prevention 2021 Report. Link: http://bit.ly/33TImUB

3. Global Initiative for Chronic Obstructive Lung Disease (GOLD) Global strategy for the diagnosis, management and prevention of COPD. 2021 Report; 2021. Link: https://bit.ly/3xZKxES

4. Uchida A, Sakaue K, Inoue H (2018) Epidemiology of asthma-chronic obstructive pulmonary disease overlap (ACO). Allergol Int 67: 165-171. Link: https://bit.ly/3xZs4sf

5. GINA-GOLD diagnosis of disease of chronic airflow limitation: asthma, COPD and asthma-COPD overlap syndrome (ACOS).

6. Woodruff PG, van den Berge M, Boucher RC, Brightling C, Burchard EG, et al (2017) American Thoracic Society/National Heart, Lung, and Blood Institute Asthma-Chronic Obstructive Pulmonary Disease Overlap Workshop Report. Am J Respir Crit Care Med 196: 375-381. Link: https://bit.ly/3kK4KuA

7. Orie NGM, Sluiter HJ (1962) Bronchitis. Assen, the Netherlands: Royal van Gorcum.

8. Wenzel SE (2012) Asthma phenotypes: The evolution from clinical to molecular approaches. Nat Med 18: 716-725. Link: https://bit.ly/3kFVMyA

9. Lambrecht BN, Hammad H, Fahy JV (2019) The cytokines of asthma. Immunity 50: 975-991. Link: https://bit.ly/3Bu4N3K
10. Woodruff PG, Modrek B, Choy DF, Jia G, Abbas AR, et al. (2009) T-Helper type 2-driven inflammation defines major subphenotypes of asthma. Am J Resp Crit Care Med 180: 388-395. Link: https://bit.ly/3kLa0yi

11. Kohansal R, Martinez-Camblor P, Agustí A, Buist AS, Mannino DM, et al. (2009) The natural history of chronic airflow obstruction revisited. Am J Resp Crit Care Med 180: 3-10. Link: https://bit.ly/2Utf3Zz

12. Elbehairy AF, Ciavaglia CE, Webb KA, Guenette JA, Jensen D, et al. (2015) Pulmonary gas exchange abnormalities in mild chronic obstructive pulmonary disease. implications for dyspnea and exercise intolerance. Am J Resp Crit Care Med 191: 1384-1394. Link: https://bit.ly/3zrm4si

13. O'Donnell DE, Flüge T, Gerken F, Hamilton A, Webb K, et al. (2004) Effects of tiotropium on lung hyperinflation, dyspnoea and exercise tolerance in COPD. Eur Respir J 23: 832-840. Link: https://bit.ly/36QfTII

14. Christenson SA, Steiling K, van den Berge M, Hijazi K, Hiemstra PS, et al. (2015) Asthma-COPD overlap: clinical relevance of genomic signatures of type 2 inflammation in COPD. Am J Respir Crit Care Med 191: 758-766. Link: https://bit.ly/3kIWWcx

15. Sin DD, Miravitlles M, Mannino DM, Soriano JB, Price D, et al. (2016) What is asthma-COPD overlap syndrome (ACOS)? Towards a consensus definition from a roundtable discussion. Eur Respir J 48: 664-673. Link: https://bit. ly/2V6fRDf

16. Nelson HS, Weiss ST, Bleecker ER, Yancey SW, Dorinsky PM (2006) The Salmeterol Multicenter Asthma Research Trial: a comparison of usual pharmacotherapy for asthma or usual pharmacotherapy plus salmeterol. Chest 129: 15-26. Link: https://bit.ly/3xX4HiX

17. Kew KM, Dahri K (2016) Long-acting muscarinic antagonists (LAMA) added to combination long-acting beta2-agonists and inhaled corticosteroids (LABA/ ICS) versus LABA/ICS for adults with asthma. Cochrane Database Syst Rev 1 : CD011721. Link: https://bit.ly/2W3gnm1

\section{Discover a bigger Impact and Visibility of your article publication with}

\section{Peertechz Publications}

\section{Highlights}

* Signatory publisher of ORCID

* Signatory Publisher of DORA (San Francisco Declaration on Research Assessment)

* Articles archived in worlds' renowned service providers such as Portico, CNKI, AGRIS, TDNet, Base (Bielefeld University Library), CrossRef, Scilit, J-Gate etc.

* Journals indexed in ICMJE, SHERPA/ROMEO, Google Scholar etc.

* OAI-PMH (Open Archives Initiative Protocol for Metadata Harvesting)

* Dedicated Editorial Board for every journal

* Accurate and rapid peer-review process

* Increased citations of published articles through promotions

* Reduced timeline for article publication

Submit your articles and experience a new surge in publication services (https://www.peertechz.com/submission).

Peertechz journals wishes everlasting success in your every endeavours.

Copyright: @ 2021 Divya K, et al. This is an open-access article distributed under the terms of the Creative Commons Attribution License, which permits unrestricted use, distribution, and reproduction in any medium, provided the original author and source are credited. 